\title{
Effect of temperature on the structural properties of barium titanate nanopowders synthesis via sol-gel process
}

\author{
M. Tihtih'1 and L. A. Gömze ${ }^{1,2,3}$ \\ 1Institute of Ceramics and Polymer Engineering, University of Miskolc, Miskolc, Hungary; \\ medtihtih@gmail.com,fememese@uni-miskolc.hu \\ 2 IGREX Engineering Service Ltd, Igrici, Hungary \\ 3 Tomsk State University, Russian Federation
}

The popularity of the research in the area of the high-tech ceramics has a great interest [1]. In the family of ferroelectrics, barium titanate $\left(\mathrm{BaTiO}_{3}\right)$ is the most frequently utilized ferroelectric material and even after seventy-five years of its disclosure, it remained as a most essential material which has excellent dielectric, optical, piezoelectric and ferroelectric properties [2]. Since the discovery of the phenomenon of ferroelectricity, $\mathrm{BaTiO}_{3}$ has been a standard material in the family of ferroelectric perovskites. This compound has been used for a long time in many industrial sectors. One of them, in full swing, is that of MLCCs Multilayer Ceramic Capacitors [3]. An interesting and very current application of $\mathrm{BaTiO}_{3}$ concerns the creation of computer memories FRAMs (Ferroelectric Random Access Memories) [4]. The manufactures of thermistors, the detection of polluting gases such as $\mathrm{CO}$ also constitute applications of $\mathrm{BaTiO}_{3}$. The properties, both optical and electrical, have proved to be very promising technologically, with, for example, the linear resonator, the sensors, the actuators, the phasing of laser sources, spatial light modulators, the guides of waves, holographic storage and high filters frequencies [5]. However, multilayer capacitors have long occupied first place in $\mathrm{BaTiO}_{3}$ applications.

Also, it is one of the most extensively studied lead-free ferroelectric materials due to its broad range of device applications as capacitors, transducers, non-volatile memories, positive temperature coefficient (PTC) thermistors and many more. Due to the importance of $\mathrm{BaTiO}_{3}$ in the field of electronics on the one hand and in order to meet the requirements of miniaturization of integrated circuits on the other hand, new preparation techniques have been developed and successfully used. The aim of these techniques is to obtain $\mathrm{BaTiO}_{3}$ at lower temperatures compared to the solid path, which results in an appreciable gain in energy and also makes it possible to use as much more modest cost metal or alloy electrodes. Among these methods we can mention the sol-gel method [6], the hydrothermal method [7] and the co-precipitation [8]. They allow having a high purity of $\mathrm{BaTiO}_{3}$ with particles very fine controllable size. Furthermore, it is possible to easily modify the physical properties of BT since these are very sensitive to doping on site $\mathrm{Ba}$, on site $\mathrm{Ti}$ and or a substitution (doping) coupled to the two sites, in view of their adaptations to very specific applications. In this work, BT materials were synthesized using sol gel method. BT was calcined at temperatures of 800 , 900 , and $1000^{\circ} \mathrm{C}$. Its aims are to determine the effects of calcination temperatures on Physical parameters such as lattice parameters, lattice strain and crystallite size of BT using X-ray diffraction XRD and Fourier-transform infrared spectroscopy (FT-IR). 


\section{References}

1. Gömze L. A. Applied materials science I. Compilation of Selected Scientific Papers. 2016. pp. 1-189.

2. Woldu T., Raneesh B., Sreekanth P., Reddy M. R., Philip R., Kalarikkal N. Size dependent nonlinear optical absorption in $\mathrm{BaTiO}_{3}$ nanoparticles // Chemical Physics Letters, 2015, 625, 58-63. https://doi.org/10.1016/j.cplett.2015.02.020

3. Park D. H., Jung Y. G., Paik U. Ceramics International, 2005, 31, 655-661. https://doi.org/10.1016/j.ceramint.2004.08.003

4. Scott J. F. Materials Science And Engineering B: Solid-State Materials For Advanced Technology,
2005, 120 (1-3), 6-12. https://doi.org/10.1016/j. mseb.2005.02.047

5. Li A. H., Zheng Z. R., Lü Q., Sun L., Xu Y. H., Liu W. L., Wu W. Z., Yang Y. Q., Lü T. Q., J. Appl. Phys. 2008104 063526. https://doi.org/10.1063/1.2982396

6. Komarneni S., Abothu I. R., Rao Et A. V. P., J. Sol-Gel Sci. Techno. 199915 263. https://doi. org/10.1023/A:1008793126735

7. Dawson W. I., Am.Ceram.Soc; Bull, 198867 (10) 1673-78.

8. Fox G. R., Adair J. H. Newnham Et R. E., J. Mater. Sci. 199025 3634. https://doi.org/10.1007/BF00575398 